\title{
Heterogeneity of iron bioavailability on plants assessed with a whole-cell GFP-based bacterial biosensor
}

\author{
Dominique C. Joyner and Steven E. Lindow
}

University of California, Department of Plant and Microbial Biology, 111 Koshland Hall, Berkeley, CA 94720-3102, USA
Author for correspondence: Steven E. Lindow. Tel: +1 510642 4174. Fax: +1 5106424995 . e-mail: icelab@socrates.berkeley.edu

Ferric iron is an essential element for microbial growth but its water solubility in aerobic environments is considered to be low. Thus it is a limiting resource for which microbes must compete in natural habitats. Since competition for iron occurs at the level of individual cells, knowledge of the variability in iron bioavailability to such individuals is required to assess the nature of the competition in these habitats. Ferric iron availability to cells of Pseudomonas syringae was assessed by quantifying the fluorescence intensity of single cells harbouring a plasmid-borne transcriptional fusion of an iron-regulated promoter from a locus encoding a membrane receptor for a pyoverdine siderophore with a reporter gene encoding green fluorescent protein (GFP) following fluorescence microscopy. Cells of this iron biosensor exhibited irondependent GFP fluorescence that was inversely proportional to the amount of iron added to the media, and which differed by over 20-fold in iron-replete compared to iron-deplete culture media. Cells cultured in a medium of a given iron content exhibited a very narrow range of fluorescence intensities. In contrast, the fluorescence intensity of cells of the biosensor strain recovered from the rhizosphere or phylloplane of inoculated bean plants varied greatly. The distribution of fluorescence intensities was strongly right-hand skewed, with about $10 \%$ of the cells exhibiting substantially higher GFP fluorescence than that of the median cell. Cells of a positive control strain, harbouring a fusion of the constitutive nptll promoter with the gfp reporter gene, exhibited uniform GFP fluorescence both in culture media and on plants. These results indicate that there is substantial heterogeneity of iron biovailability to cells of $P$. syringae on plants, with only a small subset of cells experiencing low iron availability. Such heterogeneity places constraints on models of interactions of bacteria in natural habitats that are based on competition for limited iron.

Keywords: FISH, Pseudomonas syringae, siderophore, ferric iron

\section{INTRODUCTION}

Whilst iron is the most abundant element on earth and the fourth most abundant element in the lithosphere (Ehrlich, 1990), ferric hydroxide, the most common form of iron utilized by plants and microbes (Lindsay \& Schwab, 1982; Marschner, 1995) has a solubility product $\left(K_{\mathrm{sp}}\right)$ of only $10^{-39}$ in the $\mathrm{pH}$ range $7 \cdot 4-8 \cdot 5$ (Loeppert et al., 1994). Plants require about $10^{-7 \cdot 7} \mathrm{M}$ iron in solution

Abbreviations: $C C D$, charge-coupled device; FISH, fluorescence in situ hybridization; GFP, green fluorescent protein; TAMRA, tetramethylrhodamine-5-isothiocyanate.
(Lindsay \& Schwab, 1982) to avoid iron deficiency symptoms, whereas microbes have been shown to require $10^{-8}$ to $10^{-6} \mathrm{M}$ (Guerinot, 1994; Loeppert et al., 1994). Since $\mathrm{Fe}^{3+}$ is typically predicted to have an equilibrium concentration of only about $10^{-17} \mathrm{M}$ in aerobic, aqueous environments (Guerinot, 1994), plants and microbes have evolved several means by which to acquire iron from insoluble oxide sources. Microbes solubilize iron from $\mathrm{Fe}^{3+}$ oxides through the production of low-molecular-mass iron-chelating molecules called siderophores (Guerinot, 1994) which diffuse from the organism to an iron oxide surface where catechol, hydroxamate and/or hydroxyacid functional groups 
with a high affinity for iron desorb an iron atom. The ferrated siderophore is recognized by its cognate membrane receptor and taken up by the bacterial cell; the siderophore then either undergoes structural changes which release the iron, or the iron is reduced and thus released from the siderophore (Dowling et al., 1996; Guerinot, 1994; Poole et al., 1996; Ehrlich,1990). All microbes cultured from plant surfaces produce siderophores in vitro (Loper \& Buyer, 1991). Considerable work has appeared on the yellow-green pigmented siderophores called pyoverdines produced by fluorescent pseudomonads (O'Sullivan \& O'Gara, 1992; Dowling et al., 1996; Poole et al., 1996).

Some bacteria are apparently effective in biocontrol of plant diseases due to their ability to outcompete pathogenic bacteria or fungi for iron by producing a superior iron-chelating complex with a higher affinity for iron, by producing siderophores in greater abundance, or by utilization of multiple siderophores (Raaijmakers et al., 1995a, b; Loper \& Buyer, 1991; Loper \& Ishimaru, 1991). Siderophore-mediated biocontrol also apparently occurs among members of the microbial community in fish intestines (Sugita et al., 1998). Models of iron competition have been developed to explain such interactions, such as that formulated by Buyer \& Sikora (1991), which describes how interactions which reduce the ferrated siderophore concentration in the vicinity of a cell can result in a reduction in the growth rate of that microbe. Other iron-regulated metabolites have also been implicated in the efficacy of biocontrol strains (Gill \& Warren, 1988; Leeman et al., 1996).

A variety of approaches have been taken to measure iron availability to micro-organisms at various scales. Whilst total soil iron content is often estimated following chemical extraction procedures, such measurements assess the iron content only of the bulk soil and cannot measure only that which is available to bacteria in microhabitats. The use of reporter genes linked to environmentally responsive promoters to generate biosensors has proven useful in measuring availability of a substrate of interest to microbes at small spatial scales (Jaeger et al., 1999). Loper \& Lindow (1994) have produced a whole-cell iron biosensor consisting of cells of various Pseudomonas species harbouring a transcriptional fusion of an iron-regulated promoter from a locus encoding the membrane receptor for a pyoverdine siderophore to a promoterless ice nucleation reporter gene. The ice nucleation activity of iron biosensor strains inoculated onto the bean rhizosphere or phyllosphere revealed that, on average, cells sensed $\mathrm{Fe}^{3+}$ concentrations that were intermediate between ironreplete and iron-deplete culture media (Loper \& Lindow, 1994; Marschner \& Crowley, 1997). However, the nature of the population-level information provided by the reporter genes could not eliminate the possibility that some cells on plants experienced low $\mathrm{Fe}^{3+}$ availability whilst others sensed higher $\mathrm{Fe}^{3+}$ concentrations.

A heterogeneous distribution of environmental con- ditions among microhabitats on plants (Kinkel, 1997) has been proposed as a reason for the inconsistent performance of microbial biocontrol agents (Loper \& Ishimaru, 1991). Variable colonization of plants has been attributed to variability in the distribution of carbohydrates and amino acids (Jaeger et al., 1999), and also of inorganic substances such as phosphate (Kragelund et al., 1997) and iron (Loper \& Henkels, 1997) necessary for microbial growth and colonization. Likewise, extensive exclusion of pathogens from plants by a process of iron competition requires that colonizable habitats on plants be limited in iron; this assumption has not been adequately addressed. Biological and physical processes might make iron locally abundant on plants, preventing microbial iron competition. The root tips of some plant species acidify the rhizosphere, reducing ferric iron to the utilizable ferrous form. Chemical reactions and microbial respiration (Hojberg \& Sorensen, 1993) can result in fluctuations in $\mathrm{pH}$ which in turn could affect the solubility of iron oxides, ultimately affecting the bioavailability of this element locally (Ehrlich, 1990; Loper \& Henkels, 1999; Buyer \& Sikora, 1991; Marschner, 1995; Loper \& Ishimaru, 1991). Microhabitats of bacteria may represent areas of vast chemical diversity, but this concept has not been sufficiently characterized.

This study explores the heterogeneity of available iron on plant surfaces to address ecological processes such as siderophore-mediated iron competition among bacteria on plants. To gain an understanding of the iron distribution on a small scale on plants, a whole-cell biosensor was developed to detect and measure bioavailable iron at the level of single bacterial cells. In this new biosensor, the gene encoding the green fluorescent protein (GFP) from the jellyfish Aequorea victoria replaced the inaZ reporter gene in a previously described iron biosensor. GFP formed within the biosensor cells was quantified by epifluorescence microscopy to yield estimates of the relative iron concentration sensed by individual bacterial cells on plant surfaces.

\section{METHODS}

Bacterial strains, plasmids and growth conditions. Pseudomonas syringae pv. syringae strain $\mathrm{B} 728 \mathrm{a}$, a siderophoreproducing, rifampicin-resistant pathogen isolated from a bacterial brown spot lesion on a bean leaf was used as the host strain in all studies involving fluorescence measurements. The characteristics and epiphytic behaviour of this strain have been described previously (Loper \& Lindow, 1987). Strain B728a was grown in Luria broth (LB) containing $100 \mu \mathrm{g}$ rifampicin $\mathrm{ml}^{-1}$ at $28{ }^{\circ} \mathrm{C}$ with continuous shaking. P. syringae 31R1P6(pJL1701) contains a fusion of an iron-regulated promoter from a pyoverdine biosynthesis locus $\left(\mathrm{P}_{\mathrm{pvd}}\right)$ with a promoterless inaZ ice nucleation gene on pVSP61 (Loper \& Lindow, 1994). pVSP61 is a $13.5 \mathrm{~kb}$ broad-host-range plasmid with replicons of pVS1 and pACYC184, and a determinant of kanamycin resistance, and is stably maintained in Pseudomonas species (Loper \& Lindow, 1987). Cells harbouring this fusion exhibit iron-dependent ice nucleation activity. Cells for ice nucleation assays were grown in SM medium (Loper \& Lindow, 1987) containing kanamycin $\left(50 \mu \mathrm{g} \mathrm{ml}^{-1}\right)$, which was 
supplemented with various concentrations of $\mathrm{FeCl}_{3}$ with continuous shaking at $25^{\circ} \mathrm{C}$.

A promoterless variant of a gene encoding a red-shifted green fluorescent protein $(g f p)$ and an enhanced translation initiation region from the plasmid pGreenTIR (Miller \& Lindow, 1997) were cloned downstream of the iron-regulated promoter $\mathrm{P}_{\mathrm{pvd}}$ in $\mathrm{pVSP} 61$, resulting in pVITIR (Miller \& Lindow, 1997). This plasmid was mobilized into P. syringae B728a to yield a whole-cell biosensor for $\mathrm{Fe}^{3+}$. Cells of strain B728a harbouring this gene fusion exhibited iron-dependent green fluorescence. Direct comparisons of iron-dependent ice nucleation activity and GFP fluorescence were obtained by growing both 31R1P6(pJL1701) and B728a(pVITIR) in SM media containing various concentrations of added $\mathrm{FeCl}_{3}$.

Plasmid pVSP61TIR (Miller \& Lindow, 1997) contains HindIII and BamHI sites directly downstream of an EcoRI site, in which the enhanced $g f p$ and TIR were cloned, enabling the insertion of various promoters to drive the transcription of $g f p$. Plasmid pKAN was constructed by inserting a $131 \mathrm{bp}$ sequence containing the promoter of the kanamycin resistance gene $n p t \mathrm{II}\left(\mathrm{P}_{\mathrm{kan}}\right)$ into the BamHI and HindIII restriction sites preceding the EcoRI-flanked $g f p$ in pVSP61TIR. Oligonucleotides kan-HIND (5'-GGG GGA AGC TTG ATA GCT AGA CTG GGC GG-3') and kan-BAM (5'-GCC GGA TCC CCT TGG CGG CAA GAA AGC-3') were designed to amplify the promoter region of $n p t$ II from plasmid pVSP61 (Loper \& Lindow, 1994), and to add terminal restriction sites flanking the amplified promoter region to enable its directed insertion into pVSP61TIR. The PCR product was ligated into cloning vector PCR2.1 (Invitrogen) using standard methods. The ligation mixture was electroporated into Escherichia coli JM101 using standard electroporation protocols. Insertcontaining clones were identified as blue colonies when plated on Luria agar (LA) containing X-Gal $\left(1 \mu \mathrm{g} \mathrm{ml}{ }^{-1}\right)$ and kanamycin $\left(50 \mu \mathrm{g} \mathrm{ml}^{-1}\right)$. Plasmid DNA of clones was isolated using a Qiagen DNA isolation kit. Purified plasmid DNA was phenol/chloroform-extracted, digested with HindIII/BamHI and ligated into pVSP61TIR. Plasmids were transformed into E. coli JM101, plated on LA and colonies which appeared green under UV light were identified. The plasmid in one such colony, designated pKAN, was mobilized into $P$. syringae B728a by triparental mating using E. coli(pRK2073) as a helper strain. $P$. syringae $\mathrm{B} 728 \mathrm{a}(\mathrm{pKAN})$ harbouring the $\mathrm{P}_{\mathrm{kan}}:: g f p$ fusion was used as a positive control to account for any environmental influence on plasmid copy number and efficiency of expression of GFP fluorescence, especially under non-controlled conditions on plants, because of its ironindependent expression of GFP fluorescence. These control cells were grown under the same conditions as B728a (pVITIR).

Measurement of GFP fluorescence in $P$. syringae in culture. The transcriptional activity of each promoter was estimated from measures of the GFP fluorescence of cells grown in SM medium containing a range of added $\mathrm{FeCl}_{3}$. Stationary-phase cultures grown in LB containing kanamycin $\left(50 \mu \mathrm{g} \mathrm{ml}^{-1}\right)$ were centrifuged, washed and resuspended in $10 \mathrm{ml} 10 \mathrm{mM}$ potassium phosphate buffer $(\mathrm{pH} 7 \cdot 0)$ to a concentration of approximately $10^{9}$ cells $\mathrm{ml}^{-1}$. Cells of the inoculum were transferred to SM medium containing kanamycin $\left(50 \mu \mathrm{g} \mathrm{ml}^{-1}\right)$ and $\mathrm{FeCl}_{3}$ in the range $10^{-7}$ to $10^{-3 \cdot 5} \mathrm{M}$ to a concentration of $10^{7}$ cells $\mathrm{ml}^{-1}$ and grown overnight. Cells at both midexponential and early stationary phase were rinsed in sterile distilled water, concentrated by centrifugation and diluted to an $\mathrm{OD}_{600}$ of $0 \cdot 57-0 \cdot 87$. Fluorescence measurements were made on a Perkin Elmer 510 fluorimeter with an excitation wave- length of $490 \pm 4 \mathrm{~nm}$ and an emission wavelength of $510 \pm 4$ $\mathrm{nm}$. The experiments were done in triplicate and six fluorimetric measurements were made for each sample. The fluorescence emission of cells was normalized for a final concentration of $10^{9}$ cells $\mathrm{ml}^{-1}$.

Preparation of cultured cells for fluorescence microscopy. A subsample of the washed and diluted cultures prepared for fluorimetry was used to measure fluorescence intensity of individual cells by epifluorescence microscopy. Three hundred microlitre samples were fixed in $4 \%$ paraformaldehyde as described by Amann et al. (1990). Aliquots (10 $\mu \mathrm{l})$ of fixed cells were spread on a $0.1 \%$ gelatin-coated microscope slide and air-dried. The fluorescence bleaching inhibitor Prolong (Molecular Probes) was used as a mounting medium.

Microscopy and image analysis of bacterial cells. The fluorescence of individual bacterial cells cultured in SM medium containing different iron concentrations was quantified by analysis of digital images captured using epifluorescence microscopy. The intensities of all the pixels making up the image of a single cell were averaged to yield a mean pixel intensity per cell. Images were captured using a colour chargecoupled device (CCD) camera mounted on an Axiophot epifluorescence microscope equipped with a mercury excitation lamp. GFP fluorescence was detected with a GFP Endow filter set fitted with excitation $(470 \pm 20 \mathrm{~nm})$ and emission $(525 \pm 25 \mathrm{~nm})$ filters. For image analysis, two images were taken of each field of view through a $\times 100$ objective. Cells were first visualized using phase-contrast optics. A digital image of the field was used to identify the number and location of cells in a given field. Approximately 50 cells per field were observed and 14-20 fields were counted per sample. Cells were then illuminated with blue light and green fluorescent images were captured over a $2 \mathrm{~s}$ period with the CCD camera. At a 2 s exposure time, none of the pixels in the red, green or blue channels approached the resolution limit intensity of 256 units, and the measured pixel intensity displayed the largest range. The 8-bit composite red-greenblue digital images were converted to TIFF format using Corel Photopaint software prior to image analysis. The phasecontrast images were subjected to threshold filtering whereby all pixels brighter than a given threshold value were identified and grouped into objects that defined the location of a given cell. The thresholded image was superimposed as a mask on the GFP fluorescence image. The use of the mask ensured that only pixels detailing the cell, and excluding the halo of fluorescence emitted from the cell, were selected for pixel intensity measurements. The intensity of pixels associated with the mask (which ranged from 1 to 255 pixel units) was then analysed using IP-Lab software (Signal Analytics). The measured mean pixel intensity of each cell was then transferred to Excel (Microsoft) and Statistica (StatSoft) to describe the frequency distributions of fluorescence intensities. Normal probability plots of mean cell fluorescence intensity, Kolomogorov D (Stephens, 1974) and Shapiro-Wilk (Shapiro \& Wilk, 1965) tests of normality were performed using Statistica.

Plant growth and inoculation. Bush Blue Lake 274 beans (Phaseolus vulgaris) were used in all studies. In some studies, plants were grown in a greenhouse and had indigenous bacterial populations of approximately $10^{4}$ cells $\mathrm{g}^{-1}$ when inoculated, as in previous work (Loper \& Lindow, 1994). In other studies aseptically grown plants were used. For these experiments, seeds were surface-sterilized in a solution of $25 \% \mathrm{H}_{2} \mathrm{SO}_{4}$ and $0.25 \%$ benzalkonium solution for $2 \mathrm{~h}$, followed by three washings in sterile distilled water. Seeds 
were germinated in the dark on LA plates for $3 \mathrm{~d}$. The sterility of seeds was confirmed by lack of growth of bacteria on or near the seed. Two seeds were planted per 21 flask containing a $0.5 \%$ technical agar medium made by agarizing $50 \%$ Hoaglands nutrient solution $\left(2 \mathrm{mM} \mathrm{KNO}_{3}, 5 \mathrm{mM} \mathrm{Ca}\left(\mathrm{NO}_{3}\right)_{2}\right.$, $1 \mathrm{mM} \mathrm{KH} \mathrm{PO}_{4}, 1 \mathrm{mM} \mathrm{MgSO}{ }_{4}, \mathrm{NH}_{4} \mathrm{Cl}$, trace elements and iron EDTA micronutrient solution). Plants were grown in a Percival growth chamber with a $12 \mathrm{~h}$ light $\left(25^{\circ} \mathrm{C}\right)$ and a $12 \mathrm{~h}$ dark $\left(19^{\circ} \mathrm{C}\right)$ cycle. Despite the use of sterilized seeds, populations of indigenous bacteria at the time of inoculation were around $10^{4}$ cells $\mathrm{g}^{-1}$. For rhizosphere studies, sterilized bean seeds were sown on a $0.5 \%$ water agar medium. Plants were grown on this media for 1.5-2 weeks, at which time the first leaves were fully emerged.

Plants were inoculated with $P$. syringae B728a(pVITIR) at an age of about $1 \cdot 5-2$ weeks when the primary leaves were fully developed and trifoliate leaves were first emerging. The foliage of greenhouse-grown plants was inoculated by immersing the leaves in a bacterial suspension as in previous studies (Loper \& Lindow, 1994). Aseptically grown plants were sprayinoculated using a sterilized atomizer. Leaves were kept moist for $3 \mathrm{~d}$ after inoculation before entire leaves were excised to recover bacterial cells. Inoculum was applied directly to the leaves and onto roots growing above or along the agar surface. The population size of the inoculated bacterial strain increased about 10 -fold on plants in the interval between inoculation and sampling. Cells used as inoculum were grown in LB containing kanamycin $\left(50 \mu \mathrm{g} \mathrm{ml}^{-1}\right)$, a medium containing substantial amounts of iron, until they reached early stationary phase $\left(\mathrm{OD}_{600} 1 \cdot 2\right)$. The cells were centrifuged and resuspended in $10 \mathrm{mM}$ phosphate buffer at $10^{6}$ cells $\mathrm{ml}^{-1}$. Cells of $P$. syringae $\mathrm{B} 728 \mathrm{a}(\mathrm{p}$ VITIR) grown on $\mathrm{LB}$ media were very dim, expressing GFP fluorescence that was barely detectable using fluorescence microscopy (pixel intensity $<1$ unit). Two leaves were excised, pooled and washed in $20 \mathrm{ml} 10 \mathrm{mM}$ potassium phosphate buffer. Aseptically grown root systems (weighing about 1-2 g) were vortexed, then sonicated for $7 \mathrm{~min}$, followed by vigorous vortexing for $30 \mathrm{~s}$. Microbes in suspension were concentrated by passing the plant wash solution through a $0 \cdot 4 \mu \mathrm{m}$ polycarbonate filter (Millipore) and promptly fixed in $4 \%$ paraformaldehyde.

Fluorescence in situ hybridization (FISH). The sequence of the $P$. syringae $\mathrm{B} 728$ a $16 \mathrm{~S}$ rRNA gene was determined to enable identification of a variable region. Stationary-phase cells of strain B728a were diluted to $10^{4}$ cells $\mathrm{ml}^{-1}$, and a $2 \mu \mathrm{l}$ aliquot was used as source DNA for whole-cell PCR reactions. The gene encoding the $16 \mathrm{~S}$ rRNA gene was amplified using universal $(515 \mathrm{~F}, 1492 \mathrm{R}, 1391 \mathrm{R})$ and bacterial $(8 \mathrm{~F})$ primers at an annealing temperature of $45^{\circ} \mathrm{C}$. PCR products were purified on a Sephadex 100 column (Clontech) and sequenced using $8 \mathrm{~F}-1492 \mathrm{R}$ primers in a $50 \mu \mathrm{l}$ reaction at $37^{\circ} \mathrm{C}$ using cycle sequencing. A variable region (based on the positions of homologous sequences in E. coli rRNA) was identified by comparison of the determined sequence with that of all other $16 \mathrm{~S}$ rRNA sequences in the alignment. One $21 \mathrm{bp}$ sequence, Ps1, with a minimum of two mismatches from all other entries in the rRNA database was identified. This 21 bp oligonucleotide probe sequence, 5'-ACAAGTACCCCGTGCTGCCGC$3^{\prime}$, was synthesized with an amino-modified C-6 at the $3^{\prime}$ end (Gemini). The oligonucleotide was labelled with tetramethylrhodamine-5-isothiocyanate (TAMRA; Molecular Probes) followed by PAGE purification. The lyophilized probe was dissolved in $1 \times$ TE buffer to a final concentration of $50 \mathrm{ng} \mu \mathrm{l}^{-1}$ and stored at $-20{ }^{\circ} \mathrm{C}$.
P. syringae cells were identified in mixed cell populations using FISH. Cells of Agrobacterium tumefaciens, Erwinia herbicola, Pseudomonas aeruginosa, P. syringae pv. phaseolicola and Pseudomonas fluorescens Pf5 cultured in LB, as well as cells from leaf washings of uninoculated plants, were fixed and hybridized according to a protocol described by Amann et al. (1990) with a probe concentration of $25 \mathrm{ng}$ per reaction and an incubation time of $12-18 \mathrm{~h}$ at $49^{\circ} \mathrm{C}$. Cells of strain B728a were visualized as above using a $1 \mathrm{~s}$ exposure of the same microscope field using a Chroma technologies filter set for rhodamine. The final red fluorescence image was taken after the green fluorescence image to ensure that bleaching of GFP from additional excitation did not occur. Images were subjected to threshold filtering as above and cells not corresponding to a positive hybridization signal after FISH were deleted from the GFP image. No detectable TAMRA fluorescence due to FISH was detectable under the stringency conditions that permitted bright TAMRA fluorescence of strain B728a to be observed in any cultured strain except for $P$. fluorescens strain Pf5. No cells from indigenous bacterial populations recovered from plants before inoculation yielded appreciable TAMRA fluorescence due to FISH. Thus, not only was Ps1 reasonably specific for $P$. syringae strains, but other fluorescent Pseudomonas species which might have yielded false positive signals were absent from the plants.

The application of FISH for visualization of $P$. syringae $\mathrm{B} 728 \mathrm{a}$ cells did not interfere with measurements of GFP fluorescence. The emission spectra of the TAMRA label used in FISH $(585 \pm 40 \mathrm{~nm})$ and that of GFP $(510 \pm 25 \mathrm{~nm})$ overlap slightly. However, the Endow GFP filter set used is equipped with a narrow band pass filter which is transparent to light only in the range $475-575 \mathrm{~nm}$. Thus, almost no orange fluorescence associated with a TAMRA-labelled cell was detected using the GFP filter set. No fluorescence above background was seen from parental B728a treated with the TAMRA-labelled FISH probe when viewed with the GFP filter on the epifluorescence microscope for up to $15 \mathrm{~s}$. In addition, there was no difference in pixel intensities of GFP-expressing P. syringae cells subjected to FISH using the TAMRA-labelled probe when viewed with the GFP filter set compared to cells not treated by FISH.

\section{RESULTS}

\section{Fluorescence of iron biosensor strain in culture}

Previous studies using an inaZ reporter gene showed that transcription mediated by the pvd promoter is inversely proportional to the amount of $\mathrm{Fe}^{3+}$ added to culture media (Loper \& Lindow, 1994). We measured the fluorescence of cells of $P$. syringae B728a(pVITIR), in which $\mathrm{P}_{\mathrm{pvd}}$ is fused $5^{\prime}$ to a promoterless gene encoding GFP in a fluorimeter. The fluorescence of a population of cells decreased 13-fold upon increasing the concentration of $\mathrm{FeCl}_{3}$ added to SM from $10^{-7}$ to $10^{-4} \mathrm{M}$ (Fig. 1). Addition of $10^{-3 \cdot 3} \mathrm{M} \mathrm{FeCl}_{3}$ to the medium decreased cell fluorescence to basal levels exhibited by parental strain B728a (data not shown).

The mean fluorescence intensity of individual cells visualized by fluorescence microscopy was 14 -fold lower in media containing $10^{-4} \mathrm{M}$ iron compared to that to which only $10^{-7} \mathrm{M} \mathrm{FeCl}_{3}$ was added, when corrected for background fluorescence (Fig. 1). The mean fluorescence intensity of cells cultured in various iron concentrations differed substantially (Fig. 2). A relatively narrow range 


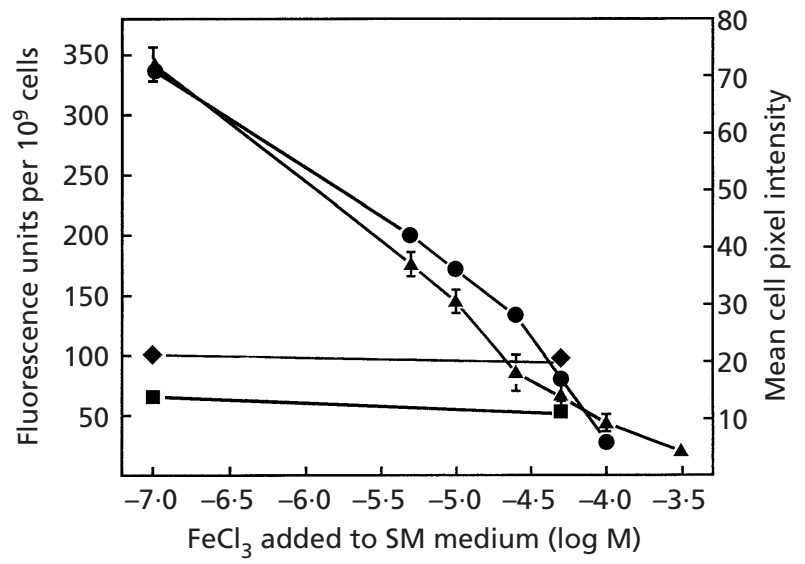

Fig. 1. Fluorescence intensities of $P$. syringae $B 728$ a containing either pKAN $(\boldsymbol{\square}, \bullet)$ or pVITIR $(\boldsymbol{\Delta}, \boldsymbol{\bullet})$ in SM media containing various amounts of added $\mathrm{FeCl}_{3}$ when measured with a fluorimeter $(\boldsymbol{\square}, \boldsymbol{\Delta})$ or determined from analysis of microscopic images $(\diamond, \boldsymbol{\bullet})$. Fluorescence intensities were normalized to $10^{9}$ cells by extrapolating from $\mathrm{OD}_{600}$ measurements. The mean fluorescence intensity of approximately 700 individual cells is shown for each iron concentration. The vertical lines represent SEM.

of fluorescence intensity was observed for cells from a given culture (Figs 2, 3b). GFP fluorescence was detected in B728a(pVITIR) in nearly all cultured cells irrespective of the iron concentration in the culture medium. Fluorescence was absent from only $0.03 \%$ of the total population of cells examined.

Measurements of the fluorescence of cells of $\mathrm{B} 728 \mathrm{a}(\mathrm{pKAN})$ harbouring a constitutive $n p t$ II promoter fused to $g f p$ were made in media containing various amounts of added $\mathrm{FeCl}_{3}$ to determine if iron bioavailability affects GFP fluorescence per se and to ensure that environmental effects on GFP fluorescence independent of $\mathrm{Fe}^{3+}$ concentration did not occur. The use of this positive control also circumvented questions that might arise regarding the formation and function of GFP under varying iron and environmental conditions and also the possible contribution of variable numbers of copies of the reporter-gene-containing plasmid on GFP fluorescence in different cells. Cells of $P$. syringae B728a(pKAN) displayed similar GFP fluorescence when grown in $\mathrm{SM}$ with added $\mathrm{FeCl}_{3}$ concentrations ranging from $10^{-7}$ to $10^{-4} \mathrm{M}$, varying only from 44 to 33 fluorescence units per $10^{9}$ cells, respectively, with a standard deviation of 4 fluorescence units (Fig. 1). These cells were also visualized by epifluorescence microscopy to quantify the GFP fluorescence intensity of individual cells from cultures containing either $10^{-7} \mathrm{M}$ or $10^{-4 \cdot 3} \mathrm{M}$ added $\mathrm{FeCl}_{3}$ (Fig. 2g, h). Cells of B728a(pKAN) grown in either iron concentration exhibited similar levels of fluorescence. More importantly, the range of fluorescence intensity among individual cells of a given culture was very small; the fluorescence intensity of cells grown in $\mathrm{SM}$ supplemented with $10^{-7} \mathrm{M} \mathrm{FeCl}_{3}$ had a range of only 28 units. This result indicates that the transcription, translation, folding and maturation of GFP was not

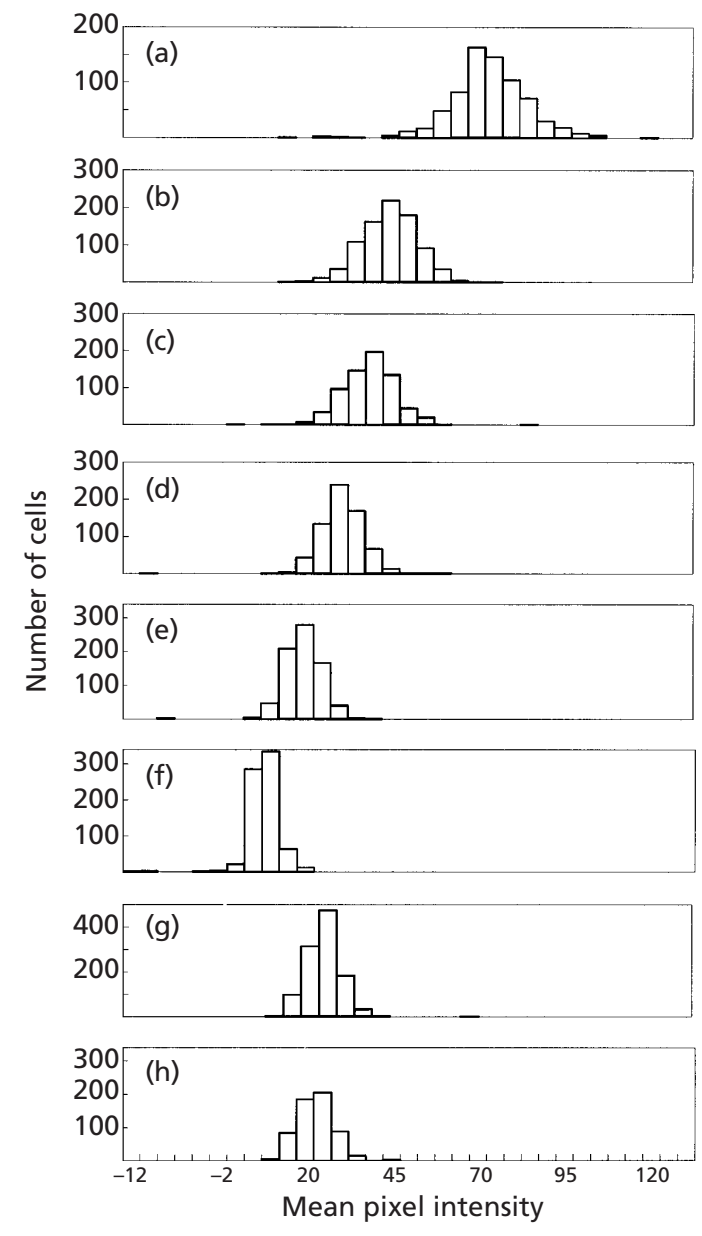

Fig. 2. (a)-(f) Iron-regulated expression of GFP in individual cells of $P$. syringae $B 728 \mathrm{a}(\mathrm{pVITIR})$ cultured in SM medium containing (a) $10^{-7} \mathrm{M}$, (b) $10^{-5 \cdot 3} \mathrm{M}$, (c) $10^{-5} \mathrm{M}$, (d) $10^{-4 \cdot 6} \mathrm{M}$, (e) $10^{-4 \cdot 3} \mathrm{M}$ or $(\mathrm{f}) 10^{-4} \mathrm{M}$ added $\mathrm{FeCl}_{3} ;(\mathrm{g})-(\mathrm{h})$ iron-independent expression of GFP in individual cells of $P$. syringae B728a(pKAN) cultured in SM medium containing (g) $10^{-7} \mathrm{M}$ or (h) $10^{-4 \cdot 3} \mathrm{M}$ added $\mathrm{FeCl}_{3}$. The mean GFP fluorescence intensity of individual cells was calculated from analysis of images captured during epifluorescence microscopy.

affected by the variable concentrations of iron to which cells were exposed. The small deviation from mean fluorescence intensity among cells also suggests that plasmid copy number in this cultured strain is relatively constant.

\section{Fluorescence of iron biosensor recovered from plants}

The fluorescence intensity of individual cells of either $\mathrm{B} 728 \mathrm{a}(\mathrm{p}$ VITIR) or $\mathrm{B} 728 \mathrm{a}(\mathrm{pKAN})$ from leaf and root washings was assessed following epifluorescence microscopy to estimate the level and variation in iron availability on leaves. The fluorescence intensity of both bacterial strains on plants was slightly lower than in culture. Environmental samples were complex in that they were littered with fluorescent plant debris and autofluorescent plant exudates (Li et al., 1997) that may 

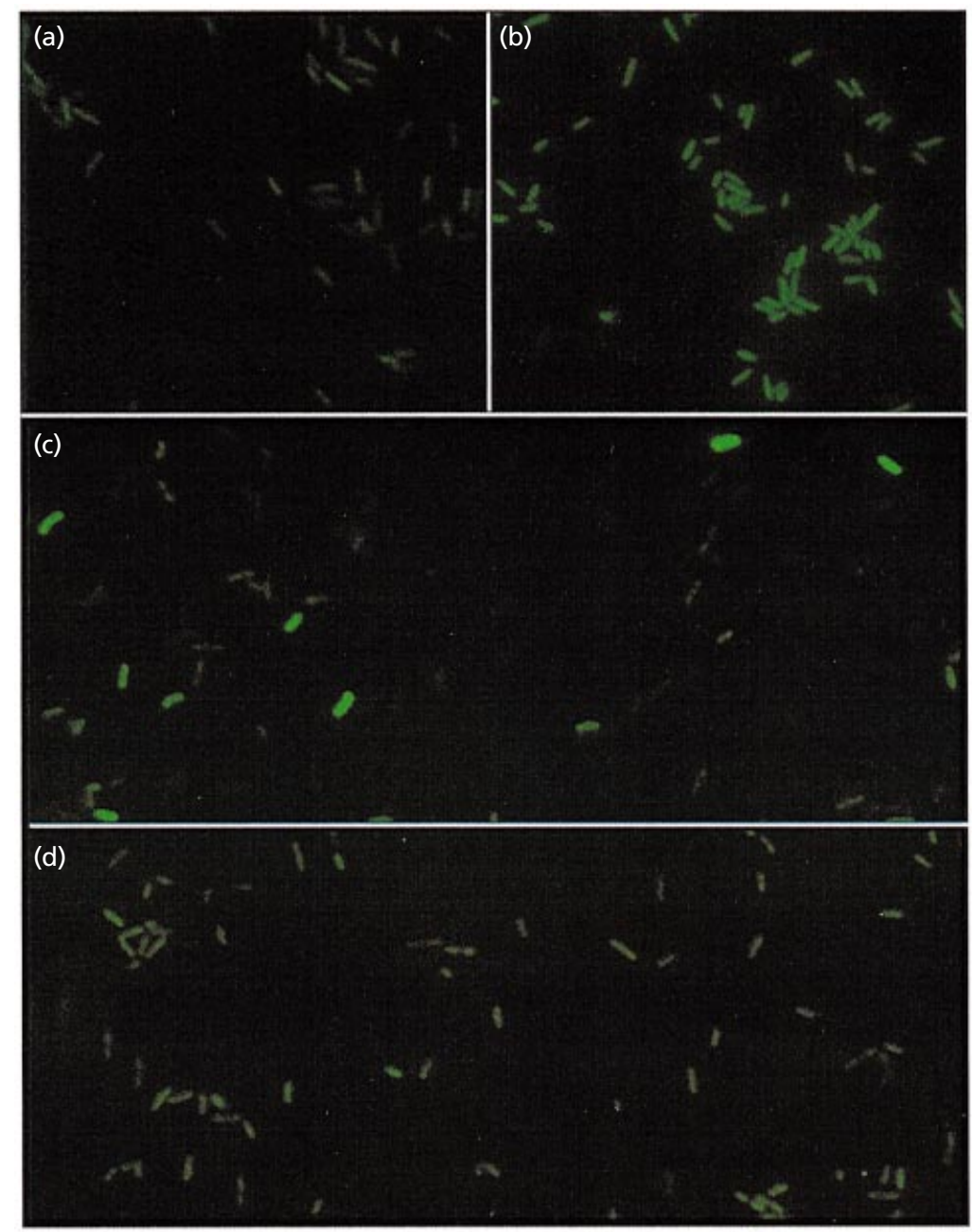

Fig. 3. Photomicrographs of cells of (a) $P$. syringae $\mathrm{B} 728 \mathrm{a}(\mathrm{pVITIR})$ grown in LB, (b) $P$. syringae $B 728 a(p V I T I R)$ harvested from $a$ culture in SM containing $10^{-5} \mathrm{M}$ added $\mathrm{FeCl}_{3}$, (c) $P$. syringae $\mathrm{B} 728 \mathrm{a}(\mathrm{pVITIR})$ washed from leaves of axenically grown bean plants, and (d) $P$. syringae B728a(pKAN) washed from leaves of axenically grown bean plants. Cells were visualized using an Axiophote epifluorescence microscope and the images were captured for $5 \mathrm{~s}$ using a CCD camera. have accounted for a slightly higher background fluorescence, which was subtracted from the fluorescence intensities of the measured cells. Whilst some cells of $\mathrm{B} 728 \mathrm{a}(\mathrm{p}$ VITIR) or $\mathrm{B} 728 \mathrm{a}(\mathrm{pKAN})$ recovered from plants were relatively dim, over $99.5 \%$ of the cells of these strains (exhibiting bright TAMRA fluorescence) had detectable GFP fluorescence; cells of the biosensor strain were thus nearly completely sampled during these studies. Background intensity corrections for both cultured and environmental samples resulted in about $0.03 \%$ of cells from these samples having an apparent negative value of pixel intensities after correction of background fluorescence; this is apparently a small artefact associated with variations in background fluorescence.

Cells of B728a(pVITIR) recovered from leaves of aseptically grown bean plants exhibited a wide range of fluorescence intensity (Fig. 3c) and displayed an asymmetric, right-hand-skewed distribution (Fig. 4a). About $10 \%$ of the cells of B728a(pVITIR) exhibited substantially higher levels of GFP fluorescence than that of the median cell. Cells analysed from a different set of aseptically grown leaves displayed a similar right-hand skewed distribution and a mean fluorescence of 10 pixel intensity units. The mean fluorescence intensity values attained from cells recovered from leaves of greenhousegrown plants and from aseptically grown roots were slightly lower than that of cells from aseptically grown plants (Fig. 4b, c, respectively). Cells washed from both greenhouse leaves and aseptic roots displayed a righthand skewed distribution in fluorescence intensities, demonstrating that some cells sensed much less $\mathrm{Fe}^{3+}$ than most.

The fluorescence intensity of cells of $\mathrm{B} 728 \mathrm{a}(\mathrm{pKAN})$ washed from aseptically grown leaves differed little between cells (Fig. 3d) and averaged 10 pixel units (Fig. 5a). Expression of pKAN in cells from aseptic root washings was only slightly higher than that from leaves (mean fluorescence intensity of 27 units) (Fig. 5b). The fluorescence intensities of cells washed from these plant surfaces were both described by normal distributions and mirrored the distribution of fluorescence of this strain in culture (Fig. $2 \mathrm{~g}, \mathrm{~h}$ ).

\section{Behaviour of iron biosensor in culture and on plants}

The growth rates of parental strain B728a and strain B728a(pKAN) in SM media were identical. Strains B728a 

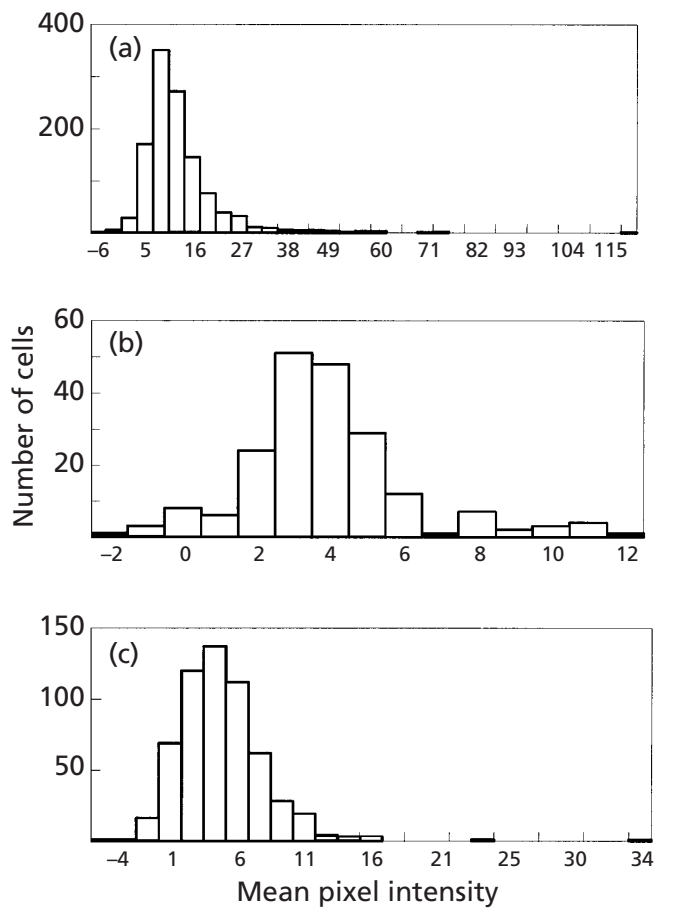

Fig. 4. Variation in GFP fluorescence intensity of individual cells of $P$. syringae $B 728 \mathrm{a}(\mathrm{pVITIR})$ recovered from plant surfaces. The mean pixel intensity of individual cells was calculated from analysis of images captured during epifluorescence microscopy of cells washed from plant surfaces. Fluorescence intensity of cells that were positively identified as B728a by FISH is shown for cells recovered $3 \mathrm{~d}$ after inoculation from (a) aseptically grown leaves, (b) greenhouse-grown bean leaves and (c) wateragar grown root systems.

and $\mathrm{B} 728 \mathrm{a}(\mathrm{pVITIR})$ also had similar growth rates to each other in SM medium containing $10^{-7} \mathrm{M}$ added $\mathrm{FeCl}_{3}$ as well as when inoculated individually onto bean leaves. The final population sizes of these two strains was also similar after $2 \mathrm{~d}$ on plants (data not shown). These results suggested that cells are not burdened by GFP production even whilst on plants. The stability of pKAN and pVITIR was assessed in P. syringae B728a by growing cells harbouring these plasmids in LB with no antibiotics for about 30 generations and then scoring for the presence of the plasmid by replica plating on rifampicin-containing medium with and without kanamycin $\left(50 \mu \mathrm{g} \mathrm{ml}^{-1}\right)$. Over $99 \%$ of the cells retained the plasmid after growth under these non-selective conditions. Likewise, over $95 \%$ of the P. syringae cells retained these plasmids after growth for up to $4 \mathrm{~d}$ on plants.

\section{Comparison of transcriptional activity of different iron biosensors on leaves}

Previous studies indicated that cells of $P$. syringae 31R1P6(pJL1701), in which $\mathrm{P}_{\mathrm{pvd}}$ is fused to a promoterless ina $Z$ reporter gene, expressed a moderate ice nucleation activity whilst on plants. This ice nucleation activity was expected of cells uniformly exposed to

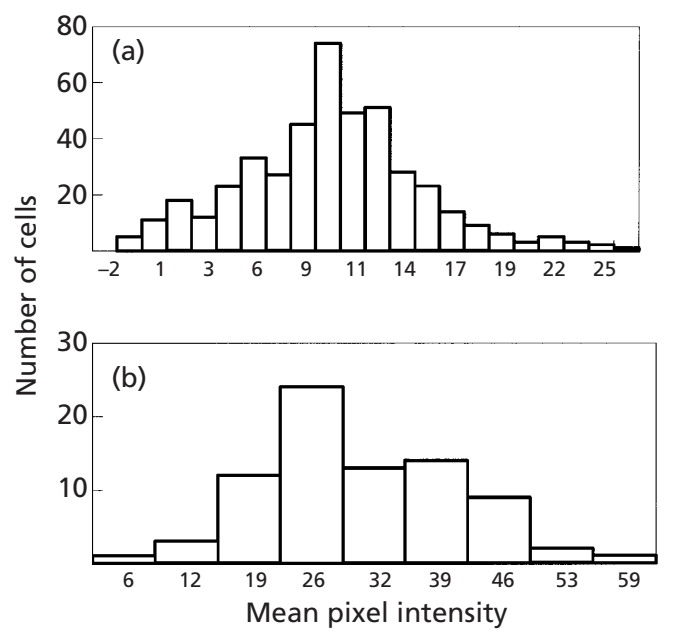

Fig. 5. Variation in GFP fluorescence intensity of individual cells of $P$. syringae B728a(pKAN) recovered from plant surfaces. The mean pixel intensity of individual cells was calculated from analysis of images captured during epifluorescence microscopy of cells washed from plant surfaces. Fluorescence intensity of cells that were positively identified as B728a by FISH is shown for cells recovered $3 \mathrm{~d}$ after inoculation from (a) aseptically grown leaves and (b) roots of plants grown in silica sand.

about $10^{-5} \mathrm{M} \mathrm{FeCl}_{3}$ (Loper \& Lindow, 1994) in SM media. A comparison study was done to determine if the range in iron availability seen on leaves measured by the $g f p$-based iron biosensor strain in this study was predictive of this mean iron concentration measured using the ice nucleation biosensor. Since the plasmid pJL1701 conferred similar levels of ice nucleation activity in cells of different strains of Pseudomonas species exposed to a given $\mathrm{Fe}^{3+}$-containing medium (Loper \& Lindow, 1994), it appeared that $\mathrm{P}_{\text {pyd }}$ was equally active and responsive to $\mathrm{Fe}^{3+}$ concentrations in different strains. Likewise, the population dynamics of $P$. syringae strains $31 \mathrm{R} 1 \mathrm{P} 6$ and $\mathrm{B} 728 \mathrm{a}$ were similar on greenhouse-grown bean plants (Beattie \& Lindow, 1994; Loper \& Lindow, 1994). Since we used the same plasmid vector in conjunction with $\mathrm{P}_{\mathrm{pvd}}$ fusions to the in $a Z$ and $g f p$ reporter genes, we felt that data from these two systems could be compared. The transcriptional activity of $p v d::$ inaZ in strain 31R1P6(pJL1701) was measured in SM supplemented with $\mathrm{FeCl}_{3}$ at concentrations ranging from $10^{-7}$ to $10^{-4} \mathrm{M}$, similar to a previous study (Loper \& Lindow, 1994). Estimates of $\log$ (ice nuclei per cell) were obtained at each iron concentration and equated to the mean fluorescence intensity of cells of B728a(pVITIR) when grown in the same medium. The mean fluorescence intensity for each cell washed from a leaf was categorized to correspond to a particular iron concentration extrapolated from a standard curve. The frequency of cells occurring within a particular range of fluorescence intensities, and thus associated with a given $\mathrm{Fe}^{3+}$ concentration, was multiplied by the ice nucleation activity calculated for cells grown in medium of that iron concentration. These values were summed over all iron concentrations and 
divided by the total number of cells to produce a predicted ice nucleation activity estimate for cells washed from the leaf. The measured mean ice nucleation activity for a population of 31R1P6(pJL1701) cells on bean leaves was $-1.4 \log$ (ice nuclei per cell) and was similar to the ice nucleation activity of $-1.2 \log$ (ice nuclei per cell) extrapolated from $g f p$ measurements.

\section{DISCUSSION}

The results of this study show that there is spatial heterogeneity of bioavailable iron on plant surfaces. The right-hand-skewed distribution in fluorescence intensities of cells from leaf washings provides evidence that some cells in a population on plants experienced low $\mathrm{Fe}^{3+}$ availability. We cannot distinguish whether iron was simply lacking from parts of these plants or whether it was present but in a form other than $\mathrm{Fe}^{3+}$. These results nonetheless support models of competition for limiting resources among microbes on plants in that at least some of the cells in a population encounter very low iron availability. The GFP protein used as a reporter of iron-dependent transcription in this study is very stable in bacteria (Lindow, 1995). The GFP fluorescence of cells of B728a(pVITIR) thus does not reflect the $\mathrm{Fe}^{3+}$ availability only at the time of sampling, but also reflects, to a lesser extent, the $\mathrm{Fe}^{3+}$ exposure history of predecessors of the sampled cell. The diminution of GFP fluorescence in our strains is apparently due primarily to dilution upon cell division, since decreases in GFP fluorescence approach as much as $50 \%$ at each generation (J. Leveau \& S. E. Lindow, unpublished). Thus GFP-fluorescent cells present at the time of sampling might have experienced a low concentration of $\mathrm{Fe}^{3+}$ shortly after inoculation and a higher subsequent concentration of $\mathrm{Fe}^{3+}$. Since cells of $P$. syringae, on average, exhibited less than about three generations of growth on the plants before sampling, cells of the iron biosensor should still exhibit higher than basal levels of GFP fluorescence even if they only transiently experienced low $\mathrm{Fe}^{3+}$ concentrations. In contrast, cells of B728a(pVITIR) rapidly express high levels of GFP fluorescence after exposure to low $\mathrm{Fe}^{3+}$ levels on leaves. Thus, had cells experienced low $\mathrm{Fe}^{3+}$ concentrations at or near the time of sampling, higher levels of GFP fluorescence would have been expected. Our results, therefore, clearly show that a majority of the bacterial population on plants experienced relatively high levels of available iron at the time of sampling that would preclude iron competition as a major mode of interaction.

Although estimates of ice nucleation activity can be performed with relatively few cells, sample sizes in most studies using inaZ as a reporter gene are at least $10^{3}$ cells (Loper \& Lindow, 1994; Loper \& Henkels, 1999; Marschner \& Crowley, 1997; Loper \& Henkels, 1997). Therefore, estimates of bioavailable iron made using the ice nucleation biosensor (Loper \& Lindow, 1994) represent a mean from a large cell population. The variation in iron availability sensed by individual microbes within this population cannot be determined using $p v d$ : inaZ gene fusions. Plant surfaces have been shown to have a variety of local factors which could be expected to create microsites where iron availability could be greatly different from the average. This study provides a higher degree of spatial resolution through utilization of a whole-cell biosensor, in which the activity of single cells was assessed to provide direct measurements of chemical resource availability within microsites at the scale of individual cells. It is noteworthy that estimates of the variation in $\mathrm{Fe}^{3+}$ concentration sensed by individual $g f p$-biosensor cells on plants in this study could accurately predict the average $\mathrm{Fe}^{3+}$ availability to a population of cells estimated by the inaZbased biosensor. This result indicates that both biosensors relate consistent estimates of $\mathrm{Fe}^{3+}$ availability, and that they differ only in the spatial scale of the estimate.

The GFP expression system enabled the quantification of fluorescence intensity that reflected the transcriptional activity of the iron-regulated $p v d$ promoter in single cells. Only a few studies have quantified GFP fluorescence to estimate promoter activity. For example, GFP fluorescence intensity of cells harbouring promoters for toluene degradation fused to $g f p$ was quantified to signal community level processes of toluene metabolism occurring between two strains making up a mixed culture biofilm (Moller et al., 1998). Likewise, mean fluorescence intensity of a small population of Yersinia enterocolitica expressing a pathogenesis-related promoter was assessed in vivo using fluorescence microscopy (Jacobi et al., 1998). Whilst laborious, quantification of GFP fluorescence of single cells is a powerful means of estimating rates of transcription.

Studies of gene expression in natural habitats are complicated by the presence of indigenous bacteria which must be distinguished from the biosensor strains. The oligonucleotide developed from the 16S rRNA sequence of $P$. syringae B728a that was used in FISH in this study distinguished cells of strain B728a from other cells in mixed samples. Few studies have used GFP and $16 \mathrm{~S}$ rRNA probes in tandem, particularly in a quantitative manner. Whilst GFP-labelled cells were used in conjunction with FISH to monitor protozoa grazing on a Pseudomonas species expressing GFP in a mixed culture sewage sludge (Eberl et al., 1997) and to detect transfer of a $g f p$-tagged TOL plasmid between members of a mixed biofilm community (Christensen et al., 1998), to our knowledge, this is the first study to measure promoter activity through the quantification of GFP fluorescence of individual cells with simultaneous FISH application for microbial identification. These studies all show that the integrity of the GFP protein is not altered by the fixation and hybridization treatments required for FISH.

Measurements of fluorescence in cells having constitutive expression of GFP from the $n p t I I$ promoter provided an analysis of factors affecting GFP synthesis and stability, as well as stability of the plasmid-borne reporter gene in natural habitats. Cells harbouring 
$n p t \mathrm{II}: g f p$ fusions exhibited moderate fluorescence that was similar between cells cultured under a range of iron conditions (Fig. 1) as well as for cells that were recovered from inoculated plants (Figs 3d, 5). Whereas factors such as plasmid copy number are uncontrolled when cells are in habitats such as plant surfaces, the use of $\mathrm{B} 728 \mathrm{a}(\mathrm{pKAN})$ as a 'positive control' revealed that such factors did not contribute to variations in expression of GFP fluorescence in these studies.

The fluorescence intensity of $\mathrm{B} 728 \mathrm{a}(\mathrm{pKAN})$ cells was slightly lower in certain plant samples than expected from cultured cells (Fig. 5). These cells were often smaller than cultured cells and hence estimates of cell fluorescence intensity were made using a smaller number of pixels that defined a cell in digital images. As a result, in both cases, pixels surrounding, but not entirely composing the microbe may have been included in those pixels used to define the cell. This 'edge effect', in which dimmer peripheral and background pixels, not entirely representative of the fluorescent cell, are counted would tend to reduce the mean intensity of cell fluorescence. If enough of these pixels were included in each cell in an environmental sample, the overall mean pixel intensities could be reduced by as much as $20 \%$. Fortunately, this effect on fluorescence intensity is small (range in fluorescence intensity in different samples of B728a (pKAN) was only about 7-19 units), and a similar overall dimming of cells harbouring an iron-dependent promoter would also be expected.

GFP expression mediated by $\mathrm{P}_{\mathrm{pvd}}$ was dramatically higher in all cells grown in low iron concentrations compared to high-iron-containing media (Fig. 2a-f). The activity of the promoter has been reported to be exclusively responsive to iron and not to other metal ions (Loper \& Lindow, 1994). Therefore, GFP expression from this strain is solely reflective of the amount of iron sensed by the microbe. Because the fluorescence of cells of B $728 \mathrm{a}$ (pVITIR) approaches zero at high iron concentrations, the greatest uncertainty of the iron environment of a cell occurs at relatively high $\mathrm{Fe}^{3+}$ concentrations. However, due to the sharp increases in GFP fluorescence intensity with decreasing iron concentration (Fig. 1), cells from iron-depleted environments can be assigned a fairly narrow range of iron concentration. Thus about $5 \%$ of the cell population on either leaves or roots could be demonstrated to experience less than the equivalent of about $10^{-6} \mathrm{M}$ added $\mathrm{Fe}^{3+}$ in SM media (Fig. 4).

The fluorescence intensities of the iron biosensor on leaves of aseptic and greenhouse-grown plants were similarly variable but generally lower on the former (Fig. 4a, b). There may be two possible explanations for the apparent higher iron availability on greenhousegrown plants. Greenhouse bean seedlings germinate through non-sterile soil containing iron and are watered with a dilute Hoaglands solution, both of which may be splashed onto leaves. Exogenous iron may be deposited onto the leaf surfaces by either of these processes, thus making iron more available to the microbes. In addition, greenhouse-grown plants harbour relatively high num- bers of indigenous bacteria. Analysis of greenhouse leaf washings by FISH revealed that approximately $35 \%$ of the microbial population washed from the plant was B728a(pVITIR), whilst the other $65 \%$ consisted of other indigenous phyllosphere inhabitants. Although the microflora of the bush beans used has not been characterized, we assumed that they include siderophore-producing microorgansims that lack the ability to utilize pyoverdines produced by B728a. As Pseudomonas species have been shown to have the capacity to utilize multiple siderophores (Loper \& Henkels, 1999), it is not unlikely that $P$. syringae strain $\mathrm{B} 728$ a could utilize the siderophores produced by at least some of the indigenous bacteria. Such cross-feeding has been noted by Loper \& Henkels (1999) on roots and would increase the apparent iron availability to some cells. The lower fluorescence intensity noted for microbes on root surfaces (Fig. 4c) may also be due to the acidification of the rhizosphere by the plants, increasing $\mathrm{Fe}^{3+}$ availability. A recent study measuring the temporal shift in iron availability in the rhizosphere has shown that iron becomes more available to microbes over time during microbial colonization of roots (Loper \& Henkels, 1997).

The data presented in this research contradict previously reported data (Marschner \& Crowley, 1997) which suggest that microbes in the rhizosphere do not encounter iron-limited conditions. The results presented here do, however, complement other studies of iron bioavailability (Loper \& Lindow, 1994; Loper \& Henkels, 1999), and also models and hypotheses regarding the iron available in microenvironments encountered by microbes on plant surfaces (Loper \& Lindow, 1994; Buyer \& Sikora, 1991) in that they show that at least a subset of the cell population does indeed encounter low iron conditions, at least occasionally on plants. Overall, the general distribution pattern of measured ferric iron availability indicates that approximately $10 \%$ of the microbes on leaves and roots in our study experienced substantial iron limitation at some point during colonization of the plant. Low rates of $\mathrm{Fe}^{3+}$-dependent promoter activity corresponding to low rates of production of siderophore complexes in over $90 \%$ of the microbes measured suggests that these microbes sensed relatively abundant iron on plants. These results indicate that interactions between microbes based on iron competition will be quite variable spatially. The results of this study demonstrate the need to better understand the characteristics of habitats encountered by microbes. Only then can we determine how these characteristics may affect microbial behaviour. Whilst not a focus of this study, the tools developed here will be useful in future studies that associate iron availability on plants with particular spatial features and processes.

\section{ACKNOWLEDGEMENTS}

The authors would like to thank Joyce Loper for her useful input regarding microbial iron metabolism; Jean-Michel 
Monier, Maria Brandl, Steve Ruzin and Denise Schichnes for help with microscopic techniques and image analysis; William Miller and Corrine Blank for advice in molecular techniques; and Aileen Haxo for technical assistance. We also thank Johan Leveau and Beatriz Quiñones for editorial suggestions on the manuscript.

\section{REFERENCES}

Amann, R. I., Krumholz, L. \& Stahl, D. A. (1990). Fluorescentoligonucleotide probing of whole cells for determinative, phylogenetic, and environmental studies in microbiology. J Bacteriol 172, 762-770.

Beattie, G. A. \& Lindow, S. E. (1994). Comparison of the behavior of epiphytic fitness mutants of Pseudomonas syringae under controlled and field conditions. Appl Environ Microbiol 60, 3799-3808.

Buyer, J. S. \& Sikora, L. J. (1991). Rhizosphere interactions and siderophores. In The Rhizosphere and Plant Growth, pp. 263-369. Edited by D. L. Keister \& P. B. Cregan. Dordrecht: Kluwer.

Christensen, B. B., Sternberg, C., Andersen, J. B., Eberl, L., Moller, S., Givskov, M. \& Molin, S. (1998). Establishment of new genetic traits in a microbial biofilm community. Appl Environ Microbiol 64, 2247-2255.

Dowling, D. N., Sexton, R., Fenton, A., Delany, I., Fedi, S., McHugh, B., Callanan, M., Moenne-Loccoz, Y. \& O'Gara, F. (1996). Iron regulation in plant associated Pseudomonas fluorescens M114: implications for biological control. In Molecular Biology of Pseudomonads, pp. 502-511. Edited by T. Nakazawa and others. Washington, DC: American Society for Microbiology.

Eberl, L., Schulze, R., Ammendola, A., Geisenberger, O., Erhart, R., Sternberg, C., Molin, S. \& Amann, R. (1997). Use of green fluorescent protein as a marker for ecological studies of activated sludge communities. FEMS Microbiol Lett 149, 77-83.

Ehrlich, H. L. (1990). Geomicrobiology of iron. In Geomicrobiology, pp. 283-346. New York: Marcel Dekker.

Gill, P. R. \& Warren, G. J. (1988). An iron-antagonized fungistatic agent that is not required for assimilation from a fluorescent rhizosphere pseudomonad. J Bacteriol 170, 163-170.

Guerinot, M. L. (1994). Microbial iron transport. Annu Rev Microbiol 48, 743-772.

Hojberg, O. \& Sorensen, J. (1993). Microgradients of microbial oxygen consumption in a barley rhizosphere model system. Appl Environ Microbiol 59, 431-437.

Jacobi, C. A., Roggenkamp, A., Rakin, A., Zumbihl, R., Leitritz, L. \& Heesemann, J. (1998). In-vitro and in-vivo expression studies of yopE from Yersinia enterocolitica using the $g f p$ reporter gene. Mol Microbiol 30, 865-882.

Jaeger, C. H., III, Lindow, S. E., Miller, W., Clark, E. \& Firestone, M. K. (1999). Mapping of sugar and amino acid availability in soil around roots with bacterial sensors of sucrose and tryptophan. Appl Environ Microbiol 65, 2685-2690.

Kinkel, L. L. (1997). Microbial population dynamics on leaves. Annu Rev Phytopathol 35, 327-347.

Kragelund, L., Hosbond, C. \& Nybroe, O. (1997). Distribution of metabolic activity and phosphate starvation response of luxtagged Pseudomonas fluorescens reporter bacteria in the barley rhizosphere. Appl Environ Microbiol 63, 4920-4928.

Leeman, M., den Ouden, F. M., van Pelt, J. A., Dirkx, F. P. M., Steijl, H., Bakker, P. A. H. M. \& Schippers, B. (1996). Iron availability affects induction of systemic resistance to Fusarium wilt of raddish by Pseudomonas fluorescens. Phytopathology 86, 149-155.
Li, S., Spear, R. N. \& Andrews, J. H. (1997). Quantitative fluorescence in situ hybridization of Aureobasidium pullulans on microscope slides and leaf surfaces. Appl Environ Microbiol 63, 3261-3267.

Lindow, S. E. (1995). The use of reporter genes in the study of microbial ecology. Mol Ecol 4, 555-566.

Lindsay, W. L. \& Schwab, A. P. (1982). The chemistry of iron in soils and its availability to plants. J Plant Nutr 5, 821-840.

Loeppert, R. H., Wei, L.-C. \& Ocumpaugh, W. R. (1994). Soil factors influencing the mobilization of iron in calcareous soils. In Biochemistry of Metal Micronutrients in the Rhizosphere, pp. 343-357. Edited by J. A. Manthey, D. E. Crowley \& D. G. Luster. Boca Raton, FL: CRC Press.

Loper, J. E. \& Buyer, J. S. (1991). Siderophores in microbial interactions on plant surfaces. Mol Plant-Microbe Interact 4, $5-13$.

Loper, J. E. \& Henkels, M. D. (1997). Availability of iron to Pseudomonas fluorescens in rhizosphere and bulk soil evaluated with an ice nucleation reporter gene. Appl Environ Microbiol 63, 99-105.

Loper, J. E. \& Henkels, M. D. (1999). Utilization of heterologous siderophores enhances levels of iron available to Pseudomonas putida in the rhizosphere. Appl Environ Microbiol 65, 5357-5363.

Loper, J. E. \& Ishimaru, C. A. (1991). Factors influencing siderophore-mediated biocontrol activity of rhizosphere Pseudomonas spp. In The Rhizosphere and Plant Growth, pp. 253-261. Edited by D. L. Keister \& P. B. Cregan. Dordrecht: Kluwer.

Loper, J. E. \& Lindow, S. E. (1987). Lack of evidence for in situ fluorescent pigment production by Pseudomonas syringae pv. syringae on bean leaf surfaces. Phytopathology 77, 1449-1454.

Loper, J. E. \& Lindow, S. E. (1994). A biological sensor for iron available to bacteria in their habitats on plant surfaces. Appl Environ Microbiol 60, 1934-1941.

Marschner, H. (1995) (editor). Mineral Nutrition of Higher Plants. New York: Harcourt Brace.

Marschner, P. \& Crowley, D. E. (1997). Iron stress and pyoverdine production by a fluorescent pseudomonad in the rhizosphere of white lupin (Lupinus albus L.) and barley (Hordeum vulgare L.). Appl Environ Microbiol 63, 227-281.

Miller, W. G. \& Lindow, S. E. (1997). An improved GFP cloning cassette designed for prokaryotic transcriptional fusions. Gene 191, 149-153.

Moller, S., Sternberg, C., Ansersen, J. B., Christensen, B. B., Ramos, J. L., Givskov, M. \& Molin, S. (1998). In situ gene expression in mixed-culture biofilms: evidence of metabolic interactions between community members. Appl Environ Microbiol 64, $721-732$.

O'Sullivan, D. J. \& O'Gara, F. (1992). Traits of fluorescent Pseudomonas spp. involved in suppression of plant root pathogens. Microbiol Rev 56, 662-676.

Poole, K., Dean, C., Heinrichs, D., Neshat, S., Krebes, K., Young, L. \& Kilburn, L. (1996). Siderophore-mediated iron transport in Pseudomonas aeruginosa. In Molecular Biology of Pseudomonads, pp. 371-383. Edited by T. Nakaazawa and others. Washington, DC: American Society for Microbiology.

Raaijmakers, J. M., Leeman, M., van Oorschot, M. M. P., van der Sluis, I., Schippers, B. \& Bakker, P. A. H. M. (1995a). Dose-response relationships in biological control of Fusarium wilt of radish by Pseudomonas ssp. Phytopathology 85, 1075-1081.

Raaijmakers, J. M., van der Sluis, L., Koster, M., Bakker, P. A. H. M., Weisbeek, P. J. \& Schippers, B. (1995b). Utilization of 
heterologous siderophores and rhizosphere competence of fluorescent Pseudomonas spp. Can J Microbiol 41, 126-135.

Shapiro, S. S. \& Wilk, M. B. (1965). An analysis of variance test for normality (complete samples). Biometrika 52, 591-611.

Stephens, M. A. (1974). EDF statistics for goodness of fit and some comparisons. J Am Stat Assoc 69, 730-737.
Sugita, H., Hinrose, Y., Matsuo, N. \& Deguchi, Y. (1998). Production of the antibacterial substance by Bacillus sp. strain NM 12, an intestinal bacterium of Japanese coastal fish. Aquaculture 165, 269-280.

Received 18 April 2000; revised 31 July 2000; accepted 3 August 2000. 